\title{
Importance of spinal deformity index in risk evaluation of VCF (vertebral compression fractures) in obese subjects: prospective study
}

\author{
Carlo Ruosi - S. Liccardo $~ \cdot$ D. Rossi • \\ G. Colella $\cdot$ C. Di Somma $\cdot$ A. Colao
}

Received: 17 August 2013/Revised: 8 September 2013/Accepted: 8 September 2013/Published online: 24 September 2013

(C) Springer-Verlag Berlin Heidelberg 2013

\begin{abstract}
Introduction Obesity and osteoporosis share many features and recent studies have identified many similarities suggesting common pathophysiological mechanisms. Obesity is associated with a higher risk of non-traumatic fractures despite bone mineral density (BMD) being normal or even increased.

Materials and methods 54 obese subjects were analyzed ( $51 \pm 16$ years, 10 males, 44 females). Spinal deformity index (SDI) is a semi-quantitative method that may be a surrogate index of bone microarchitecture. SDI index was higher in patients than in controls. In $87.5 \%$ of patients and $10 \%$ of controls we found morphometric vertebral fractures, despite a DEXA Tscore not diagnostic of osteoporosis.

Conclusion The objective of this study was to assess in obese patients levels of $25 \mathrm{OH}$ vitamin $\mathrm{D}$, parathyroid hormone, serum and urinary calcium $(\mathrm{Ca})$ and phosphorus (P), BMD, and SDI. $87.5 \%$ of the obese subjects present nontraumatic vertebral fractures and reduced bone quality as measured by SDI.
\end{abstract}

Keywords Osteoporosis · Obesity $\cdot$ Spinal deformity index $\cdot$ Vertebral fractures

C. Ruosi $(\bowtie)$ - S. Liccardo · D. Rossi · G. Colella

Department of Orthopaedics, University of Naples "Federico

II", Via Pansini 5, 80131 Naples, Italy

e-mail: caruosi@unina.it

C. Di Somma

SDN Foundation Naples, University "Federico II", 80131 Naples, Italy

A. Colao

Dipartimento di Medicina Clinica e Chirurgia, University

"Federico II", 80131 Naples, Italy

\section{Introduction}

Obesity and osteoporosis share many features, although until now they have been considered mutually exclusive. Recent studies highlighted a lot of similarities between obesity and osteoporosis suggesting common pathophysiological mechanisms: (I) they are influenced by common genetic and environmental factors; (II) both start their development during the early adolescence to fully manifest themselves in adulthood, (III) osteoblasts (the cells responsible for bone formation) and adipocytes arise from a common precursor: mesenchymal stem cell; (IV) both are linked with oxidative stress and highly increased production of pro-inflammatory cytokines. In this context, several mechanisms to explain the complex relationship between adipose and bone tissues have been proposed. It is well known that mechanical stress exerted on the bones by body mass lead to an increase in bone mass to support the increased load. In addition a low BMI represents a risk factor for a reduced mass and increased bone loss [1]. Adipose tissue also represents a major source of aromatase enzyme activity, which synthesizes estrogens from androgens, and estrogens play a recognized anti-osteoporotic role. Nevertheless, the protective effects of body weight may not fully compensate the negative effects of obesity on bone. The adipose tissue, in fact, is an active endocrine organ, able to secrete molecules such as leptin, adiponectin, and inflammatory cytokines such as interleukin-6 (IL6) and tumor necrosis factor (TNF- $\alpha$ ) that may not only precipitate adverse metabolic and cardiovascular effects, but are also involved in the regulation of bone metabolism. A cross-sectional study of 16,573 individuals in the third National Health and Nutrition Examination Survey (NHANES) (1984-1994) showed that the odds ratio for elevated serum levels of C-reactive protein (CRP) were 
positively associated with body mass index (BMI); in other studies, CRP, IL-6, and leptin were directly related to the adiposity degree. The pro-inflammatory cytokines, including TNF- $\alpha$, IL-1, and IL- 6 , are mediators of bone resorption stimulating osteoclasts' activity via the regulation of RANKL/RANK/OPG pathway. Moreover, the overexpression in adipose tissue of 11beta-hydroxysteroid dehydrogenase (11beta-HSD) type-1 isozyme, which converts inactive cortisone into active cortisol, may contribute to an inhibitory effect of adipose tissue on bone formation due to higher conversion rate in active glucocorticoids. Both adipocytes and osteoblasts, as previously mentioned, arise from mesenchymal stem cell: current knowledge suggests that the activation of PPAR- $\gamma$ promotes the differentiation of mesenchymal stem cells versus adipocytes rather than versus osteoblasts; on the other side, the Wnt/ $\beta$ catenin signaling pathway inhibits adipogenesis, promoting osteoblastogenesis.

\section{Patients and methods}

\section{Patients}

Between March and October 2011, 61 consecutive obese patients referred both to the Departments of Endocrinology and Orthopaedics of Federico II University in Naples were enrolled in this study after their written informed consent. This study included women and men with obesity, according to World Health Organization (WHO) diagnostic criteria: normal weight, BMI $<24.9 \mathrm{~kg} / \mathrm{m}^{2}$; overweight, $25<$ BMI $<29.9 \mathrm{~kg} / \mathrm{m}^{2} ;$ obesity, BMI $>30 \mathrm{~kg} / \mathrm{m}^{2}$. The exclusion criteria were patients affected by diseases associated with bone impairment, such as Cushing's syndrome, hypothyroidism, hyperthyroidism, prolactinoma, hyperparathyroidism, renal failure, malabsorption, chronic alcohol intake or heavy smoking, and medications that might affect bone and mineral metabolism. After the exclusion of 4 patients with hyperthyroidism and 3 patients with primary hyperparathyroidism, 54 patients (10 male, 44 female, mean age $56 \pm 11$ years) were studied. Twenty-two female obese were postmenopausal and not taking hormone replacement therapy and 22 were premenopausal women. Among obese subjects, $48 \%$ had obesity class I, $32 \%$ obesity class II and $20 \%$ obesity class III. None of the patients was treated with thiazolidinediones or incretins. Among patients, $85.7 \%$ used antihypertensive therapy, in particular $40 \%$ used ACE inhibitors, $30 \%$ used angiotensin II receptor antagonists, $20 \%$ used calcium channel blockers, and $10 \%$ used b-blockers. $50 \%$ of patients had hypercholesterolemia treated with HMGCoA reductase inhibitors that had no detrimental effects on bone. All patients underwent a clinical, biochemical, and BMD examination. Fifty-four sex, age, and BMI-matched subjects served as controls. Clinical, biochemical, and BMD characteristics of the 54 patients and controls are shown in Table 1.

Methods

\section{Clinical assessment}

Height, weight, BMI, systolic blood pressure, and diastolic blood pressure were evaluated by standard methods. BMI was measured as ratio between weight and the square of the height. A BMI between 25 and $30 \mathrm{~kg} / \mathrm{m}^{2}$ was considered suggestive of being overweight, whereas BMI $>30 \mathrm{~kg} / \mathrm{m}^{2}$ was considered to be suggestive of obesity; mild, moderate, and severe obesity were described by a BMI of 30.0-34.9, 35.0-39.9, and 40, respectively. Blood pressure was measured at the right arm, with subjects in a relaxed sitting position. The average of six measurements (three taken by each of two examiners) taken with a mercury sphygmomanometer was used. Hypertension was diagnosed when diastolic blood pressure values were $>85 \mathrm{mmHg}$ and systolic blood pressure values were $>130 \mathrm{mmHg}$ in line with Adult Treatment Panel III.

\section{Biochemical assessment}

Glycemia, glycated hemoglobin (HbA1c), total cholesterol, HDL-cholesterol, triglycerides, uremia, creatinine, calcium, phosphorus, albumin, and total alkaline phosphatise (ALP) were determined on serum samples at fasting by automated techniques (Roche Modular System). Intact PTH (parathormone) were measured by the Clauss method. Serum levels of $25-\mathrm{OH}$ vitamin D were measured with chemiluminescence (DiaSorin, Italy). Vitamin D deficiency was defined as a serum concentration of $25-\mathrm{OH}$ vitamin $\mathrm{D}$ below $20 \mathrm{ng} / \mathrm{ml}$, insufficiency between 20 and $30 \mathrm{ng} / \mathrm{ml}$, and normal levels for values $>30 \mathrm{ng} / \mathrm{ml}$ [2]. Urinary calcium, phosphorus, and creatinine were also measured on 24-h urine samples.

\section{Instrumental investigation}

BMD was measured by DEXA at spine and femoral neck (Machinery HOLOGIC QDR 1000, USA). DEXA measures areal BMD in $\mathrm{g} / \mathrm{cm}^{2}$ using ionizing radiation with photon beams of two different energy levels, $T$-score, the standard deviation (SD) from mean value obtained in 30-year-old normal subjects, and Z-score, the SD from mean value obtained in subjects of same age and sex. A $T$-score $-1 \mathrm{SD}$ or greater was considered normal, between -1 and -2.5 SD was consistent with osteopenia, lower than $-2.5 \mathrm{SD}$ was consistent with osteoporosis, and lower 
Table 1 Clinical, biochemical and BMD characteristics of patients and controls as whole and women according to menopause

\begin{tabular}{|c|c|c|c|c|c|c|}
\hline & $\begin{array}{l}\text { Obese patients } \\
N=54\end{array}$ & Controls $N=56$ & $\begin{array}{l}\text { Pre-menopausal women } \\
N=20\end{array}$ & Post-menopausal women & $\mathrm{P}_{1}$ & $\mathrm{P}_{2}$ \\
\hline Age (years) & $51 \pm 16$ & $52 \pm 10$ & $38 \pm 9$ & $64 \pm 8$ & 0.726 & 0.000 \\
\hline BMI $\left(\mathrm{Kg} / \mathrm{m}^{2}\right)$ & $36 \pm 6$ & $24 \pm 6$ & $39.1 \pm 6$ & $35 \pm 6$ & 0.000 & 0.018 \\
\hline Glycemia (mg/dl) & $96 \pm 18$ & $93 \pm 15$ & $94.2 \pm 23$ & $97.7 \pm 17$ & 0.349 & 0.662 \\
\hline Creatinine (md/dl) & $0.8 \pm 10.2$ & $0.9 \pm 0.2$ & $0.4 \pm 0.3$ & $0.8 \pm 0.1$ & 0.943 & 0.034 \\
\hline Calcium (mg/dl) & $9.3 \pm 0.4$ & $9.2 \pm 0.3$ & $9.3 \pm 0.3$ & $9.2 \pm 0.5$ & 0.145 & 0.774 \\
\hline Urinary calcium $(\mathrm{mg} / \mathrm{die})$ & $183 \pm 160$ & $150 \pm 20$ & $205.8 \pm 100$ & $170 \pm 101$ & 0.136 & 0.540 \\
\hline Phosphorus (mg/dl) & $3.6 \pm 0.5$ & $4.0 \pm 0.2$ & $3.5 \pm 0.5$ & $3.7 \pm 0.6$ & 0.000 & 0.119 \\
\hline $25 \mathrm{OH}$ vitamin $\mathrm{D}(\mathrm{ng} / \mathrm{ml})$ & $23.9 \pm 10$ & $30.4 \pm 14$ & $23 \pm 10$ & $24.7 \pm 10.9$ & 0.007 & 0.640 \\
\hline Parathormone $(\mathrm{pg} / \mathrm{ml})$ & $55.2 \pm 29$ & $37 \pm 5.3$ & $51.6 \pm 24.7$ & $57.9 \pm 32.1$ & 0.000 & 0.483 \\
\hline Total alkalinephosphatase (U/l) & $94 \pm 57$ & $94 \pm 12.3$ & $71.5 \pm 56.0$ & $115 \pm 70$ & 1 & 0.055 \\
\hline Cholesterol (mg/dl) & $212 \pm 54$ & $147 \pm 40$ & $204 \pm 46$ & $218 \pm 60$ & 0.000 & 0.423 \\
\hline Triglycerides (mg/dl) & $145 \pm 80$ & $137 \pm 32$ & $162 \pm 107$ & $131 \pm 49$ & 0.497 & 0.244 \\
\hline Lumbar BMD (g/cm²) & $1.089 \pm 0.1$ & $0.996 \pm 0.08$ & $1.250 \pm 0.2$ & $1.018 \pm 0.1$ & 0.000 & 0.03 \\
\hline Lumbar $T$ score & $0.1 \pm 1.7$ & $0.1 \pm 1.1$ & $1.5 \pm 1.4$ & $-0.4 \pm 1.4$ & 1 & 0.04 \\
\hline Lumbar $Z$ score & $0.9 \pm 1.4$ & $-0.1 \pm 0.4$ & $1.4 \pm 1.33$ & $0.7 \pm 1.5$ & 0.000 & 0.284 \\
\hline Femoral BMD $\left(\mathrm{g} / \mathrm{cm}^{2}\right)$ & $0.841 \pm 0.1$ & $0.936 \pm 0.05$ & $1.048 \pm 0.1$ & $0.777 \pm 0.1$ & 0.000 & 0.000 \\
\hline Femoral $T$ score & $-0.6 \pm 1.4$ & $-0.1 \pm 0.5$ & $0.9 \pm 0.9$ & $-1.23 \pm 1.0$ & 0.015 & 0.047 \\
\hline Femoral $Z$ score & $0.0 \pm 0.9$ & $0.0 \pm 0.4$ & $0.8 \pm 0.5$ & $-0.1 \pm 0.8$ & 1 & 0.000 \\
\hline SDI & $4 \pm 3.3$ & $0.32 \pm 0.2$ & $1.67 \pm 1.1$ & $4.33 \pm 3.4$ & 0.000 & 0.001 \\
\hline
\end{tabular}

$P_{1}$ Significance of obese patients vs. controls

$P_{2}$ Significance of premenopausal women vs. postmenopausal women

than -2.5 SD or less with a fragility fracture was consistent with severe osteoporosis [3].

A dorsolumbar spine radiography was performed in the anteroposterior and laterolateral projections in all patients to assess vertebral fractures; these were performed by measuring three vertebral heights (anterior, mean, and posterior) of each vertebra between T4 and L4 and by calculating the percentage of fracture; fractures were considered mild if fracture index was between 20 and $25 \%$, moderate between 25 and $40 \%$, and severe if $>40 \%$. For SDI calculation a value of 0 was assigned to vertebrae without fracture, a value of one to mild fractures, a value of two to moderate fractures, and a value of three to severe fractures; the sum of these values represents SDI index. SDI is a semi-quantitative index that integrates number and severity of fractures and has been suggested as an estimate of bone microarchitecture, a bone quality parameter.

\section{Statistical analysis}

The statistical analysis was performed by SPSS for Windows version 15 (SPSS, Inc., Chicago, IL, USA). Data were expressed as mean \pm SD. ANOVA was used as the case, followed by Newman-Keuls test for comparison between groups. Student's $t$ test was used for intergroup comparison, while non-parametric test Mann-Whitney
$U$ test was utilized when necessary. The correlation analysis by Pearson's coefficient was assessed to study the correlation between numerical data. The $p$ values were given for these analyses. The significance was set at $5 \%$.

\section{Results}

Among patients, $48 \%$ had mild obesity, $32 \%$ moderate obesity, and $20 \%$ had severe obesity. The vitamin D levels were significantly lower in obese patients than in controls (23.9 \pm 10 vs. $30.4 \pm 14, p=0.007)$. A severe deficiency of vitamin $\mathrm{D}(<20 \mathrm{ng} / \mathrm{dl})$ was present in $37 \mathrm{vs.} 4 \%$, a state of deficiency in $40 \%(20-30 \mathrm{ng} / \mathrm{ml})$ vs. $52 \%$, and normal levels of vitamin D (>30 ng/dl) in 22 vs. $44 \%$, respectively, in obese subject and normal-weight controls. Moreover, the average serum concentration of PTH was at the high limits of the normal range ( $\mathrm{PTH}=55.2 \pm 29 \mathrm{pg} /$ $\mathrm{ml}$ ) and not associated with an increase of calcemia. At lumbar spine, $76 \%$ of patients had normal values of $T$ score, $20 \%$ had osteopenia and $4 \%$ had osteoporosis, and at femoral neck $T$-score was normal in $59 \%$, between -1 and -2.5 in $31 \%$, and in $9 \%$ of cases $<-2.5$, therefore, diagnostic, respectively of osteopenia and osteoporosis. The values of $Z$-scores were normal for the age of the patients at both lumbar spine and femoral neck (Table 1). 
Patients and controls significantly differed in lumbar BMD $T$-score and $Z$-score $(1.089 \pm 0.1$ vs. $0.996 \pm 0.08$, $p=0.00 ; 0.1 \pm 1.7$ vs. $0.7 \pm 1.1, \mathrm{p}=003 ; 0.9 \pm 1.4$ vs. $-0.1 \pm 0.4, p=000)$ and femoral BMD and $T$-score $(0.841 \pm 0.1$ vs. $0.936 \pm 0.05, p=0.00 ;-0.6 \pm 1.4$ vs. $-0.1 \pm 0.5, p=0.015) .75 \%$ of patients and $17 \%$ of controls $\left(\chi^{2}=67.96, P=0.000\right)$ had radiographic vertebral fractures, and these were mild in 28 patients and 12 controls, moderate in 16 patients and 5 controls, and no patient had severe fractures. SDI index was higher in patients than in controls $(4 \pm 3.3$ vs. $0.32 \pm 0.2$, $p=0.000)$. The percentage of patients with fractures with a $T$-score $>-2.5$, and therefore not diagnostic of osteoporosis was $87.5 \%$ in patients and $10 \%$ in controls ( $\left.\chi^{2}=46.55, P=0.000\right)$. In obese patients BMI, as reported in other studies, was directly related to lumbar BMD and $T$-score $(r=0.51, p=0.007$ and $r=0.52$, $p=0.007)$ and with femoral BMD and $T$-score $(r=0.40$, $p=0.05$ and $r=0.49, p=0.005)$; moreover, SDI index was directly correlated only with age $(r=0.417$, $p=0.043$ ).

\section{Conclusions}

This study shows that obese patients, despite normal BMD, as evidenced by the values of the $T$-score, present a possible deterioration in bone architecture and increased prevalence of vertebral fractures, as demonstrated by the increased value of the SDI, compared to controls. In addition, more than $50 \%$ of patients with at least one vertebral fracture had a normal BMD or osteopenia, but not osteoporosis, and this occurred in a significantly higher rate in patients than in controls, suggesting that in this population the BMD analysis by MOC DEXA may not represent an accurate instrument to estimate the risk of fracture.

Vertebral fractures, together with those of the femur and radius are the most common associated with osteoporosis (fragility fractures) and the presence of at least one of these increases the risk of further fragility fractures in all regions [5-7]. For that reason, severity of vertebral fractures represents a clinical marker of bone weakness and a predictor of risk of new fractures, regardless of the value of BMD, as well as being suggestive of an architectural deterioration of bone [8]. Moreover it was observed that, among the multiple vertebral fractures (MVFs), discontinuous MVFs (fractures in skipped vertebrae) are generally caused by mild outer force and often occur at the thoracolumbar junction, while continuous MVFs (fractures in successive vertebrae), frequently, are caused by high-energy trauma [9].

The bone microarchitecture is considered one of the components of the bone quality [10], whose alteration has been associated with vertebral fractures regardless of
BMD; the problem in the use of this diagnostic parameter is that this can be evaluated directly only with the histomorphometric analysis or with microtomography or invasively on a sample of bone biopsy [11, 12]. SDI index integrates both number and severity of vertebral fractures in a single parameter [4] and has recently been proposed as an indirectly surrogate marker of bone microarchitecture [13]. This study for the first time evaluated the use of SDI in patients with obesity. Patients had also sub-optimal values of $25 \mathrm{OH}$ vitamin $\mathrm{D}$, lower than $30 \mathrm{ng} / \mathrm{ml}$ [14]. This condition of hypovitaminosis $\mathrm{D}$, likely, was responsible for the high levels of PTH, close to the standard limits in patients evaluated; instead, calcium values were maintained within normal range. In line with this observation, Sukumar et al. identified in obese women before and after menopause, increased levels of serum PTH and low vitamin D, compared with controls, assuming that the reduced bioavailability of vitamin $\mathrm{D}$ may be secondary to the sequestration of vitamin $\mathrm{D}$ in adipose tissue. Other studies have described an increased risk for fractures in obesity: Preamor et al. analyzed a group of 1,500 postmenopausal women who reported fractures and found that $19.3 \%$ of these have mild obesity and $8,4 \%$ had moderate and severe obesity and 59 and $73 \%$, respectively, had a normal BMD at both lumbar and femoral. These results indicated that obesity may be a risk factor for fractures, and that the high BMD values represent an adaptive response to increased skeletal load, but do not give a real protection against fracture risk [15-18]. Another study on the prevalence of vertebral fractures in postmenopausal women had stressed that, despite body weight and BMI positively correlated to BMD, these parameters were also associated with a higher probability of at least one vertebral fracture, assuming that a reduced bone quality could represent a determinant of a reduced strength and increased fracture. In this study, BMI was positively correlated with BMD, the $T$ score and $Z$-score at the lumbar spine, while $81 \%$ of obese patients had at least one vertebral fracture, and of these only $33 \%$ had a $T$-score $<-2.5 \mathrm{SD}$, able to predict the presence of fractures. SDI index integrates both number and severity of vertebral fractures in a single parameter and has been recently proposed as a surrogate marker of bone microarchitecture [4] and its use has already been validated by Chiodini et al. [19] in patients with hypercortisolism due to adrenal incidentaloma and by our group in diabetic patients [20], in whom, despite a normal BMD, an increased prevalence of fractures was observed. According to Tauchmanovà et al. [21] also endogenous hypercortisolism has negative effects on bone density, bone turnover, and fracture incidence.

However, no correlation was found between anthropometric parameters and the SDI in obese patients, although this may be due to the small size of the study population. 
On the other hand also Kerkeny et al. [22] in his prospective study shows that the number and the severity of vertebral fractures have a strong impact on further vertebral fracture risk in postmenopausal women with osteoporosis. Also for him, SDI is a convenient tool to assess this risk in this population.

In conclusion, the use of BMD, traditional parameter for the definition of osteoporosis, and the most modern algorithms for the assessment of fracture risk, including the FRAX (WHO fracture risk assessment tool), may not be sufficient to identify fracture risk in obese patients. The number and severity of prevalent vertebral fractures are important predictors of future risk of fracture in obese patients.

SDI has proved to be a useful index of risk for vertebral fractures in both obese patients and in those with postmenopausal osteoporosis; for these reasons SDI is the major index in postmenopausal obese women.

Patients with the highest SDI should receive the highest priority to treatment.

\section{Conflict of interest None}

\section{References}

1. Ravn P, Cizza G, Bjarnason NH, Thompson D, Daley M, Wasnich RD, McClung M, Hosking D, Yates AJ, Christiansen C (1999) Low body mass index is an important risk factor for low bone mass and increased bone loss in early postmenopausal women. Early Postmenopausal Intervention Cohort (EPIC) study group. J Bone Miner Res 14(9):1622-1627

2. Holick MF, Binkley NC, Bischoff-Ferrari HA, Gordon CM, Hanley DA, Heaney RP, Murad MH, Weaver CM (2011) Evaluation, treatment, and prevention of vitamin D deficiency: an Endocrine Society clinical practice guideline. J Clin Endocrinol Metab 96(7):1911-1930

3. World Health Organization, Assessment of fracture risk and its application to screening for postmenopausal osteoporosis (1994) Report of a WHO study group. World Health Organ Tech Rep Ser 843:1-129

4. Crans GG, Genant HK, Krege JH (2005) Prognostic utility of a semiquantitative spinal deformity index. Bone 37:175-179

5. Kanis JA (2002) Diagnosis of osteoporosis and assessment of fracture risk. Lancet 359:1929-1936

6. Lindsay R, Silverman SL, Cooper C, Hanley DA, Barton I, Broy SB, Licata A, Benhamou L, Geusens P, Flowers K, Stracke H, Seeman E (2001) Risk of a new vertebral fracture in the year following a fracture. JAMA 285:320-323

7. Burger H, van Daele PL, Algra D, Hofman A, Grobbee DE, Schutte HE, Birkenhager JC, Pols HA (1994) Vertebral deformities as a predictors of non vertebral fractures. BMJ 309:991-992

8. Delmas PD, Genant HK, Crans GG, Stock JL, Wong M, Siris E, Adachi JD (2003) Severity of prevalent vertebral fractures and the risk of subsequent vertebral and non vertebral fractures: results for the MORE trial. Bone 33:522-532

9. Kano S, Tanikawa H, Mogami Y, Shibata S, Takanashi S, Oji Y, Aoki T, Oba H, Ikegami S, Takahashi J (2012) Comparison between continuous and discontinuous multiple vertebral compression fractures. Eur Spine J 21(9):1867-1872

10. NIH Consensus Development Panel (2001) Osteoporosis prevention diagnosis and therapy. JAMA 285:785-795

11. Thomsen JS, Ebbesen EN, Mosekilde L (2002) Predicting human vertebral bone strength by vertebral static histomorphometry. Bone 30:502-508

12. Link TM, Majumdar S, Grampp S, Guglielmi G, van Kuijk C, Imhof H, Glueer CC, Adams JE (1999) Imaging of trabecular bone structure in osteoporosis. Eur Radiol 9:1781-1788

13. Genant HK, Delmas PD, Chen P, Jiang Y, Eriksen EF, Dalsky GP, Marcus R, San Martin J (2007) Severity of vertebral fracture reflects deterioration of bone microarchitecture. Osteoporos Int 18:69-76

14. Holick MF, Binkley NC, Bischoff-Ferrari HA, Gordon CM, Hanley DA, Heaney RP, Murad MH, Weaver CM, Endocrine Society (2011) Evaluation, treatment, and prevention of vitamin D deficiency: an Endocrine Society clinical practice guideline. J Clin Endocrinol Metab 96(7):1911-1930

15. Seeman E, Melton LJ III, O'Fallon WM, Riggs BL (1983) Risk factors for spinal osteoporosis in men. Am J Med 75:977-983

16. Albala C, Yáñez M, Devoto E, Sostin C, Zeballos L, Santos JL (1996) Obesity as a protective factor for postmenopausal osteoporosis. Int J Obs Relat Metab Disord 20:1027-1032

17. Pesonen J, Sirola J, Tuppurainen M et al (2005) High bone mineral density among perimenopausal women. Osteoporos Int 16:1899-1906

18. Henry MJ, Pasco JA, Sanders KM, Nicholson GC, Kotowicz MA (2006) Fracture risk (FRISK) score: geelong osteoporosis study. Radiology 241:190-196

19. Chiodini I, Morelli V, Masserini B, Salcuni AS, Eller-Vainicher C, Viti R, Coletti F, Guglielmi G, Battista C, Carnevale V, Iorio L, Beck-Peccoz P, Arosio M, Ambrosi B, Scillitani A (2009) Bone mineral density, prevalence of vertebral fractures, and bone quality in patients with adrenal incidentalomas with and without subclinical hypercortisolism:an Italian multicenter study. J Clin Endocrinol Metab 94(9):3207-3214

20. Di Somma C, Rubino M, Faggiano A, Vuolo L, Contaldi P, Tafuto N, Andretti M, Savastano S, Colao A (2013) Spinal deformity index in patients with type 2 diabetes. Endocrine 43(3):651-658

21. Tauchmanovà L, Pivonello R, De Martino MC, Rusciano A, De Leo M, Ruosi C, Mainolfi C, Lombardi G, Salvatore M, Colao A (2007) Effects of sex steroids on bone in women with subclinical or overt endogenous hypercortisolism. Eur J Endocrinol 157(3):359-366

22. Kerkeni S, Kolta S, Fechtenbaum J, Roux C (2009) Spinal deformity index (SDI) is a good predictor of incident vertebral fractures. Osteoporos Int 20(9):1547-1552 